Article

\title{
Exploring the Strategic Inclinations of Japanese Environmental NPOs in Post-Fukushima Japan
}

\author{
Mark Heuer * (iD) and Shan Yan \\ Sigmund Weis School of Business, Susquehanna University, Selinsgrove, PA 17870, USA; yan@susqu.edu \\ * Correspondence: heuer@susqu.edu
}

Received: 18 January 2018; Accepted: 28 February 2018; Published: 9 March 2018

\begin{abstract}
Following Sine and David's research on the potential of environmental jolts shifting the status quo in U.S. energy policy, we focus on the potential for environmental non-profit organizations in Japan to shift the status quo through institutional entrepreneurial efforts following the environmental jolt from the Fukushima nuclear power catastrophe. We evaluate the institutionalization of energy policy in Japan both pre- and post-Fukushima as the context for examining the potential for change in Japan's energy policy. We utilize mixed qualitative and quantitative research methods to evaluate the attitudes and strategic inclinations of privately funded Japanese environmental non-profit organizations. Following Dreiling and Wolf's model of material-organizational dependencies versus ideological motivations of non-profit organizations, we develop a typology to identify which, if any, segments of environmental Japanese non-profit organizations might pursue institutional entrepreneurial (Levy and Scully) opportunities in support of renewable energy policy.
\end{abstract}

Keywords: non-profit organizations; environment; Japan; nuclear energy; renewable energy

\section{Introduction}

The 2011 Fukushima nuclear power accident offers a diverse context, culturally and politically, for testing the hypothesis developed by Wise and David [1] that environmental "jolts" led to shifts in the status quo of U.S. energy policy in the U.S. following the 1973 Arab oil embargo and the resulting energy crisis. The appropriateness of comparing U.S. energy policy shifts with the potential for the same in Japan finds support from Broadbent who offers: "with its Western institutions but Eastern cultural background, Japan represents the perfect case of 'experimental' variation in this task [growth versus environmental strategy]. If Western theories hold in Japan, they should hold anywhere." [2] (p. 6).

Japan's status as the world's second largest economy and its intention to play a leading role in climate change policy following the Kyoto Council of Parties meeting in 1997 stands in stark contrast to the uncontrolled nature of the Fukushima nuclear disaster, which left more than 1600 dead [3]. Hasegawa [4] described the disaster as follows:

"the largest disaster in Japan since World War II. This accident is a human disaster which an electric company and the national government are very much responsible for due to a series of 'underestimates', such as that of the height of a possible tsunami, the possibility of a station blackout and lengthy periods of no AC power. A lot of confusing and misleading information, along with deliberate concealment of information and delay in information disclosure occurred. Located in the background of all of this is the 'Atomic Circle', a very closed relationship between politicians, government, academics, industry, and the media. We should try and learn from all of this in building a post-nuclear East Asia. This would be the greatest lesson from the tragic Fukushima disaster and the greatest message to East Asia, the world and future generations." 
The complexity of Japanese society complicates the future of environmental Non Profit Organizations (NPOs) and energy policy as a whole in Japan. The embeddedness of the Ruling Triad (Atomic Circle, as referenced by Hasegawa) in terms of cultural, political, and economic power deeply influences the political opportunities and potential for mobilizing policy options for environmental NPOs in pursuit of renewable energy alternatives in the post-Fukushima context. Indeed, elites in Japan with access to political or economic power are often supportive of the Ruling Triad. Moreover, the power of the bureaucracy, especially The Ministry of the Economy, Trade and Industry (METI), results in deeply embedded support for nuclear energy, which is provided by nine Electric Power Companies (EPCOs), which operate as geographic monopolies. The EPCOs control the electric power grid, which industrial scale renewable energy producers must access through Feed in Tariffs (FiTs). The FiTs can be adjusted to increase the price of renewable energy and thereby influence the scale and scope of environmental NPOs and the growth of renewable energy sources [5].

However, the Fukushima catastrophe, and the role of the Ruling Triad in it, stands in stark contrast to the "economic miracle of the 1960's and its speedy reduction in air and water pollution compared to its wealthy counterparts, such as the U.S. and Germany" [2]. This then raises the question pertinent to this paper in terms of addressing possible institutional entrepreneurial opportunities for environmental Japanese NPOs: "What political processes and larger social structures brought about Japan's reduction in air pollution, unmatched in the West, yet in so many other environmental issues, led to default?" [2].

More specifically, what is the opportunity for institutional change regarding the status quo of Japanese energy policy, which favors nuclear energy, given the environmental "jolt" of the Fukushima catastrophe? What is the possibility for environmental NPOs in Japan to bring about at least incremental change in energy policy towards greater support for renewable energy?

The Kyoto Third Conference of Parties (COP3) to the UN Framework Convention on Climate Change in 1997 allowed new and existing NPOs in Japan to connect with global environmental organizations. This exposure assisted Japanese NPOs in gaining access to the resources and capabilities of global environmental organizations. Additionally, the 1998 Nonprofit Organization Law provided the opportunity for legal status for Japanese NPOs, but did not provide for tax exempt contributions and required extensive registration requirements with the government [6]. Regarding the institutional structure of NPOs, Academic A1 [7] noted that the NPO law created the opportunity for bureaucratic capture of environmental NPOs as some companies utilized the opportunity to fund new NPOs and place retired employees on the board of the NPO. The creation and funding of NPOs added to an array of environmental NPOs. With the passage of the NPO law, the Japanese environmental NPO institutional structure included: (1) established, private NPOs; (2) new, private NPOs; (3) business-funded NPOs; and (4) global NPOs, which increased in number, scale and scope after the Kyoto COP. The result was confusion and uncertainty about the strategic inclinations of environmental NPOs, as it became possible for a pro-nuclear energy NPO to have a name indicative of a pro-renewable energy NPO.

We address these questions by first providing background (see Appendix A) (pre- and post-Fukushima) on Japanese NPOs and the Ruling Triad's role in influencing environmental NPO strategic inclinations regarding Japan's energy policy. We then provide a literature review and theory development section to further explicate the possibilities for change in Japanese energy policy based on Sine and David's [1] hypothesis. This leads to a proposition regarding the possibility for institutional entrepreneurship by non-elites in support of renewable energy institutional structures and policy. The methodology section includes an explanation of the qualitative and quantitative approaches utilized to develop background information about environmental Japanese NPOs and then quantitatively survey their attitudes about Japanese energy policy. We conclude with a discussion section in which Dreiling and Wolf]'s [8] material-organizational dependencies model is used to build a typology of Japanese environmental NPOs. We identify segments of Japanese NPOs based on the model and explain the strategic inclinations of these segments and the likelihood of a segment or segments to achieve at least incremental support for renewable energy. 
However, the inadequate response by the government and TEPCO, the operator of the Fukushima plant, intensified public anxiety about nuclear power. The electricity system had difficulty coping with the shortages caused by the accident. For example, electricity surpluses in some regions could not offset shortages elsewhere due to inadequate interconnection facilities. In addition, weak market mechanisms forced the government to cope with shortages by relying on inefficient policies, such as rolling blackouts and across-the board cuts, as well as increased usage of fossil fuel-based generation systems [4].

\section{Literature Review and Theory Development}

Recognizing the paucity of research on the relationship between institutional change and entrepreneurship, Sine and David [1] studied the U.S. electric power industry over a 40-year period and concluded that environmental jolts can mobilize actors to reformulate institutions. This mobilization can be the catalyst for change even in the face of embedded institutional structures, but only in environments marked by scarcity and crisis. However, in environments where there is abundance, such as the plentiful and cheap availability of gasoline in oil prior to the 1973 Arab oil embargo, change did not occur and the status quo remained intact. Sine and David (2003) indicate that, post-1973 during the energy crisis, shifts in U.S. energy policy occurred, such as the requirement for utilities to purchase energy from nontraditional sources, such as renewable energy.

In this article, we consider Sine and David's theory in the context of Japan. We posit that the Fukushima disaster qualifies as an "environmental jolt" through which political opportunities to shift energy policy toward renewable energy could occur, given the safety concerns of nuclear power. However, there are significant differences between the institutional structures of the U.S. and Japan. Broadbent and Ishio note that the power of the Japanese government exists through its embeddedness in networks of trust, resources, and communication. "Through these networks, the government provides guidance, or state formulation, of business policies. Business trusts the state to absorb business' concerns and give good collective guidance" [9] (p. 79).

The trust of the Japanese people to be treated well by the government relates to the Japanese culture of paternalism and trust toward power-dominant figures and organizations. The loss of trust lies at the heart of the evolving relationship between the Ruling Triad and private, environmental NPO's in Japan. If the Fukushima disaster presents an opportunity for environmental NPOs to mobilize civil society in demanding the phasing out of nuclear energy, the extent of the opportunity lies in whether the loss of embedded trust is enough of a factor to sever the Ruling Triad's (including TEPCO) historical, culturally reinforced bond with Japanese civil society. The issue of trust is explained by $\mathrm{NPO} 2[7]$ :

“Japanese are concerned about climate change and its consequences, but people don't want a public display. There is a lack of grass roots. Even today, more than $60 \%$ do not support the restart of nuclear power plants. After 4 years, many are concerned about nuclear, but we are not so fully successful in supporting non-nuclear policy.

Regarding U.S. NPO's, if we look back 200-300 years, the U.S. was built by people from a severe environment in Europe, so they don't trust the guidance of government as much.

In Japan, we have been governed by relatively good people because of the traditional culture. Leaders were not so cruel or stupid-they controlled people nicely, so people responded with trust". A hierarchical belief system, supported by Buddhism and Shintoism, survived the introduction of Western influences. This belief system can be explained partially by Hofstede's national culture dimension of "uncertainty avoidance" [10]. Hofstede's uncertainty avoidance measure ranks Japan as having the 7th highest uncertainty avoidance score (92), while the U.S. at 46 is 43 rd out of 50 nations, with the mean of 50 and a standard deviation of 24 . Hofstede's uncertainty avoidance provides a stark contrast between Japan and the U.S., which are recognized generally with different approaches toward management and decision making. Key attributes of "uncertainty avoidance" are "less risk taking, resistance to change, fear of failure, preference for consensus decision making, rule-bound behavior, 
and respect for tradition" [10]. These attributes coincide with the trusting attitude of Japanese society toward the Ruling Triad. Jones and George [11] refer to this as "unconditional trust" in that shared values structure the social situation. Trust in this scenario involves a willingness to rely on another party and make one's self vulnerable.

The embeddedness of the Ruling Triad further complicates the issue of trust. The electric power infrastructure involves nine EPCOs (electric power companies), all of which have geographic monopolies. These EPCOs control the grid and work with METI and the Liberal Democratic Party (LDP) to maintain mutually reinforcing relationships, according to NPO1 [7]. While the current situation in Japan involves partially deregulated electric power, the EPCOs and the Ruling Triad can limit access and affordability of renewable energy. TEPCO's finances have been severely damaged by the Fukushima disaster, even with the government bailout of TEPCO [5]. Thus, for TEPCO, the restart of reactors is crucial for rehabilitating its finances [12]. Rapid growth of renewable energy runs counter to this objective. According to NPO3 [7], "EPCOs find renewable energy threatening because it can hurt the monopolized system and investment in nuclear power. They are concerned about losing power to local governments. They lobby the Diet to protect their interests." The loss of trust in TEPCO can be described as a shift from unconditional trust to a conditional trust, based on TEPCO correcting its behavior to regain the unconditional trust that had existed prior to the Fukushima catastrophe [11]. There is now uncertainty so that a willingness to be vulnerable in the case of unconditional trust does not exist at present [13]. Conditional trust does not nullify uncertainty avoidance but creates a greater willingness to consider change.

This scenario, which applies in varying degrees to all Japanese EPCOs, raises the question of the degree to which private, environmental NPOs can take advantage of potentially favorable political opportunities, as theorized by Sine and David [1]. Broadbent [2] suggests that the "political opportunity structure" in Japan may differ from the West because of basic institutional or cultural differences. We propose that the influence of the Ruling Triad on environmental NPOs in Japan has impacted the institutional structure of the NPOs, particularly in terms of financial support and ideological leanings of NPO organization officers. This institutional structure and influence differs from the U.S. in terms of influencing the status quo [1]. Therefore:

Proposition 1. In institutional environments involving trust in an embedded elite and bureaucratic paternalism, a loss of trust in institutions due to a cataclysmic event, or jolt, can support institutional entrepreneurialism involving non-elites pursuing institutional structures and policies external to the institutional status quo.

Hardy and Maguire [14] note that "those actors that are located at the periphery—by being less embedded in and less privileged by existing institutional arrangements-have more to gain from change, but may lack the power and resources to realize it." p. 199. As suggested by the interviewees about the possibility for a stronger renewable energy in Japan, we theorize that private environmental NPOs will act as "challengers to the established status quo by working around or outside channels to build parallel, alternative systems of organizations" [15].

To support our proposition, we draw on Dreiling and Wolf's [8] model of material-organizational dependencies versus ideological motivations of NPOs to develop a typology to identify which, if any, segments of environmental Japanese NPOs might pursue institutional entrepreneurial [16] opportunities in support of renewable energy policy. The Dreiling and Wolf model is based on the motivations for environmental organizations in the U.S. to either oppose or support the North American Free Trade Agreement (NAFTA). They propose that the "political difference among environmental groups over NAFTA is related to how both frame issues facing the environment and what material resource environmental organizations rely on for support." p. 43. More specifically, certain conservation and business groups stressed the importance of environmental and business issues complementing each other, while preservation and environmental justice groups saw the term "free trade" as code for destroying the environment in favor of profit [8]. 


\section{Methodology}

The methodology in this paper involves a two-step process of interviewing managers with five Japanese environmental organizations, followed by a statistical analysis of 46 Japanese environmental NPOs. The interviews resulted from contacting 46 EOs at least twice with interview questions and a request for a personal interview. Those NPOs interviewed were those that responded to the interview requests. Interviews occurred in person at the NPO home offices (four in Tokyo and one in Kyoto) during October-December 2015. Questions and general topics were submitted to the NPOs prior to the interview. The interviews used semi-standardized techniques involving predetermined questions and topics, while also allowing the freedom to digress and for the interviewer to probe beyond the answers to the prepared and standardized questions [17]. Information from the interviews is utilized throughout this paper to clarify the strategic inclinations of the NPOs, as well as to gain insight into the challenges involved in supporting energy policy at odds with the Ruling Triad. Based on interview information, opposition to nuclear power is considered generally equivalent to support for renewable energy.

The 46 EOs were selected by Academic A2 from the Environmental Restoration and Conservation Agency (ERCA) database of 2185 Japanese EOs (environmental NPOs). ERCA was established by the Japan Fund for Global Environment through an endowment from the Japanese government and contributions from the private sector [18]. More than 90 percent of the EOs on ERCA have no English web page, which eliminated them from the sample because statements about opposing or supporting nuclear energy on an EO's website is a primary variable utilized in this research. As indicated in Table 1, Academic A2 selected the 46 EOs based on:

1. Availability of an English name of the EO;

2. Data available on the financial levels, oppositionality toward nuclear energy, and the founding year of the organization;

3. Available contact information such as an email address, telephone number, and physical address; and

4. A representative sample of EOs with differing levels of oppositionality toward nuclear power post-Fukushima.

Oppositionality towards nuclear energy, the primary dependent variable, is categorized as follows:

- $\quad 0$ : nothing expressed about nuclear electric power plant issues;

- 1: state the facts about nuclear electric power but not necessarily oppositional;

- 2: hold conference or host study groups/publish in bulletin or blog about nuclear;

- 3 : insist to revise energy policy;

- 4: oppose and insist on the gradual phase out/place responsibility on nuclear industry or government; and

- 5: strongly oppose nuclear power, insist on immediate shut down of power plants, and condemn TEPCO and government.

In addition to oppositionality, the annual budget of the NPO and the age of the NPO, defined as the number of years since an NPO's founding, are included to determine if funding levels and age are correlated with oppositionality. The annual budget is reported as a value between 1 and 4 , as follows (in Yen):

- 1: 0-1 million

- 2: 1-10 million

- 3: 10-100 million

- 4 : >100 million

Table 1 reports the summary statistics of the NPO opposition level. Opposition is defined as following: 0: nothing expressed about nuclear electric power plant issues; 1 : state the facts 
about nuclear electric power but not necessarily oppositional; 2: hold conference or host study groups/publish in bulletin or blog about nuclear; 3: insist to revise energy policy; 4: oppose and insist on the gradual phase out/place responsibility on nuclear industry or government; and 5: strongly oppose nuclear power, insist on immediate shut down of power plants, and condemn TEPCO and government. Budget is defined as following; The annual budget is reported as a value between 1 and 4 , as follows (in Yen): 1: 0-1 million; 2: 1-10 million; 3: 10-100 million; and 4: >100 million. Age is defined as years since the founding of the organization.

Table 1. Summary Statistics of NGO Interview Sample in Japan.

\begin{tabular}{|c|c|c|c|c|c|c|c|c|}
\hline \multicolumn{9}{|c|}{ Panel A: Sample Summary Statistics } \\
\hline $\mathbf{N}$ & Standard & Error & p25 & p50 & Mean & p75 & Min & Max \\
\hline opposition & 46 & 1.960 & 0 & 3 & 2.609 & 4 & 0 & 5 \\
\hline Budget & 46 & 0.695 & 3 & 3 & 3.304 & 4 & 1 & 4 \\
\hline Age & 46 & 17.443 & 20 & 26 & 32.391 & 38 & 12 & 82 \\
\hline \multicolumn{9}{|c|}{ Panel B: Sort on Opposition Summary Statistics } \\
\hline \multicolumn{9}{|c|}{ opposition $=0$} \\
\hline $\mathbf{N}$ & Standard & Error & \multicolumn{2}{|c|}{ p50 } & \multicolumn{2}{|c|}{ Mean } & Min & Max \\
\hline Budget & 13 & 0.599 & \multicolumn{2}{|c|}{4} & \multicolumn{2}{|c|}{3.769} & 2 & 4 \\
\hline Age & 13 & 16.132 & \multicolumn{2}{|c|}{26} & \multicolumn{2}{|c|}{33.692} & 12 & 66 \\
\hline \multicolumn{9}{|c|}{ opposition $=1$} \\
\hline Budget & 2 & 0.000 & \multicolumn{2}{|c|}{4} & \multicolumn{2}{|c|}{4.000} & 4 & 4 \\
\hline Age & 2 & 1.414 & \multicolumn{2}{|c|}{19} & \multicolumn{2}{|c|}{19.000} & 18 & 20 \\
\hline \multicolumn{9}{|c|}{ opposition $=2$} \\
\hline Budget & 5 & 0.447 & \multicolumn{2}{|c|}{3} & \multicolumn{2}{|c|}{3.200} & 3 & 4 \\
\hline Age & 5 & 23.456 & \multicolumn{2}{|c|}{34} & \multicolumn{2}{|c|}{41.200} & 17 & 67 \\
\hline \multicolumn{9}{|c|}{ opposition $=3$} \\
\hline Budget & 6 & 0.632 & \multicolumn{2}{|c|}{3} & \multicolumn{2}{|c|}{3.000} & 2 & 4 \\
\hline Age & 6 & 7.679 & \multicolumn{2}{|c|}{23} & \multicolumn{2}{|c|}{24.167} & 14 & 36 \\
\hline \multicolumn{9}{|c|}{ opposition $=4$} \\
\hline Budget & 10 & 0.527 & \multicolumn{2}{|c|}{3.5} & \multicolumn{2}{|c|}{3.500} & 3 & 4 \\
\hline Age & 10 & 25.372 & \multicolumn{2}{|c|}{23} & \multicolumn{2}{|c|}{36.800} & 13 & 82 \\
\hline \multicolumn{9}{|c|}{ opposition $=5$} \\
\hline Budget & 10 & 0.516 & \multicolumn{2}{|c|}{3} & \multicolumn{2}{|c|}{2.600} & 2 & 3 \\
\hline Age & 10 & 9.571 & & & 29. & & 16 & 47 \\
\hline
\end{tabular}

Table 1 also reports the budget variable based on the opposition level and age, from 0 to 5 .

Table 2 below reports the Pearson correlation coefficients among opposition level, budget and age of NPO in Japan.

Table 2. Correlation Analysis.

\begin{tabular}{cccc}
\hline & Opposition & Budget & Age \\
\hline \multirow{3}{*}{ Budget } & Opposition & 1 & \\
Age & $-0.5304 * * *$ & 1 & 0.0001 \\
& -0.0357 & $0.3309 *$ & 1 \\
& & 0.8137 & 0.0247 \\
\hline \multicolumn{4}{c}{ Statistical significance ${ }^{*} p<0.1 ; * * *<0.01}$.
\end{tabular}

Opposition is defined as following: 0: nothing expressed about nuclear electric power plant issues; 1: state the facts about nuclear electric power but not necessarily oppositional; 2: hold conference or host 
study groups/publish in bulletin or blog about nuclear; 3: insist to revise energy policy; 4: oppose and insist on the gradual phase out/place responsibility on nuclear industry or government; and 5: strongly oppose nuclear power, insist on immediate shut down of power plants, and condemn TEPCO and government. Budget is defined as following; The annual budget is reported as a value between 1 and 4 , as follows (in Yen): 1: 0-1 million; 2: 1-10 million; 3: 10-100 million; and 4: >100 million. Age is defined as years since the founding of the organization.

The strong negative relationship between the budget level and opposition suggests that, the higher the amount of funding in an NPO's budget, the stronger the likelihood that the NPO will not take a strong oppositional stance toward nuclear energy through statements on its website. This result is consistent with observations of NPOs and academics that, especially since the legalization of NPOs in 1998, businesses have provided funding and placed retired managers on the boards of NPOs and this has reduced opposition toward nuclear energy.

Table 3 reports the linear regression results of Japan NPO opposition. The dependent variable is the NPO opposition level. The independent variables are NPO budget and age of NPOs.

Table 3. Regression of Opposition Level.

\begin{tabular}{ccc}
\hline & $\mathbf{( 1 )}$ & $\mathbf{( 2 )}$ \\
\hline Variables & Opposition & Opposition \\
\hline \multirow{2}{*}{ Budget } & $-1.496^{* * *}$ & $-1.643^{* * *}$ \\
& $(0.403)$ & $(0.375)$ \\
\hline Age & 0.018 & $(0.016)$ \\
\hline Constant & $7.552^{* * * *}$ & $7.465^{* * *}$ \\
& $(1.360)$ & $(1.350)$ \\
\hline Observations & 46 & 46 \\
\hline R-squared & 0.281 & 0.303 \\
\hline F statistics & 13.78 & 10.01 \\
\hline Standard errors in parentheses, ${ }^{* * *} p<0.01$.
\end{tabular}

Opposition is defined as the following: 0: nothing expressed about nuclear power issues; 1 : states the facts about nuclear electric power but not necessarily oppositional; 2: holds conferences or hosts study groups/publishes in bulletins or blog posts about nuclear; 3: insists on revising energy policy 4: opposes and insists on the gradual phase out/places responsibility on the nuclear power industry; and 5: strongly opposes nuclear power, insists on immediate shut down of power plants, and condemns TEPCO and government. The annual budget is reported as a value between 1 and 4 , as follows (in Yen): 1: 0-1 million; 2: 1-10 million; 3: 10-100 million; and 4: >100 million.

\section{Discussion}

As suggested by the data analysis, the strategic opportunities for environmental NPOs in Japan and their ability to pursue institutional entrepreneurial efforts in support of renewable energy remains limited because of the Ruling Triad's deeply embedded network involving government, the LDP, and business, which support nuclear power and oppose renewable energy. The closed system of the Ruling Triad or Atomic Circle as described by Hasegawa [4], extends to business funding of NPOs supportive of nuclear power and is buttressed by METI's bureaucratic control of energy policy [5].

Historically, political efforts in Japan opposing nuclear energy, which started right after the beginning of the government's nuclear energy policy in the 1950s, have had limited influence due to the monopoly power of the energy companies and the tight knit nature of the Ruling Triad [5].

The current situation in Japan involves a partially deregulated energy environment, greater international focus on climate change and renewables due to COP21, and a loss of public trust in the government on energy policy and execution. While this situation offers policy opportunities 
for renewable energy, the fact remains that the EPCOs and the Ruling Triad can limit access and affordability of renewable energy to the Japanese public. This scenario, which applies in varying degrees to all Japanese EPCOs, raises the question of the degree to which private, environmental NPOs can take advantage of potentially favorable political opportunities to for renewable energy support.

There are legitimate reasons to be skeptical about the potential for success of private, environmental NPOs in Japan in overcoming the pro-nuclear energy support of the Ruling Triad, including the political elites and EPCOs. In this case, government and business in Japan have already funded many NPOs in Japan. However, the renewable energy alternative presents an option less dependent on elites and one capable of institutional change based on a decentralized network involving local governments and cooperatives. Miyadai [19] refers to this approach as the "communal self-government" of energy which is growing in preference in the U.K. and Germany.

\section{A Contingency Model for Strategic Inclinations of Japanese Environmental NPOs}

Following the model developed by Dreiling and Wolf [8] for evaluating policy positions of environmental movement organizations in the U.S. based on their material dependencies (i.e., sources of income), their ties with corporate and political entities, and the ecological identities of the environmental nonprofits, the following contingency model evaluates Japanese environmental NPOs based on institutional embeddedness and ideological intensity. While the model of Dreiling and Wolf (2001) considers material dependence, ties, and ecological identities to evaluate a binary result of "anti-NAFTA" or "pro-NAFTA", the contingency model in Table 4 considers gradations of embeddedness and ideological intensity based on the six levels of oppositionality to nuclear energy identified by Academic A2 [7].

Table 4. Institutional Responses of Japanese Environmental NPO's Institutional Embeddedness. Degree of Embeddedness.

\begin{tabular}{ccc}
\hline & Low & High \\
\hline $\begin{array}{c}\text { Ideological I High } \\
\text { Intensity l Low }\end{array}$ & Transformers & Reformers \\
Conformers & Accommodators \\
\hline
\end{tabular}

Reformers indicate private, environmental NPOs in Japan ideologically committed to renewable energy but also embedded in the existing system in that their strategies involve using the FiT mechanism and accessing the EPCOs' grid system to execute their strategies.

In the Kansai region, local governments are pursuing a decentralized approach. An example is The Union of Kansai Governments, which consists of seven prefectural governments (Kyoto, Osaka, Shiga, Hyogo, Wakayama, Tottori, and Tokushima) and four government-ordinance-designated city governments (Kyoto, Osaka, Sakai, and Kobe) in the Kansai region. The Union released the Kansai Energy Plan in March 2014. In this plan, the Union aims to triple the output of solar energy and other renewable energies to 6 million kilowatts in 2020 [20].

In addition, NPO4 set up the Japan Community Energy Association, which involves a growing network of NPO-local government interdependent relationships:

"local power is a very big part of the answer. Local governments are looking at community power. We will use the FiT scheme for PV, wind, etc. We also need some heat such as biomass, solar thermal or geothermal heat pumps" (NPO4 interview [7].

Additionally, NPO5 has initiated a similar effort by advocating Citizens Co-Owned Power Plants since 2000:

"The Fukushima accident greatly affected [increased] the interest of local communities in co-owned power plants". In addition, advocates on climate change and advocates against nuclear power both favor more renewable energy, so this improves the interest in renewable power and co-owned plants. While 400 projects were undertaken prior to FiT, after FiT, projects grew because 
FiT helps with understanding Return on Investment. FiT assures sale of power to electric company. This allows for predictability which helps with investor interest. Banks would not loan before FiT.

With only two nuclear power plants currently in operation while safety evaluations are conducted on the other plants, Japan is forced to meet its electric power needs through strict conservation and increased use of fossil fuel imports. Given the breadth and depth of the Ruling Triad's network, the private environmental NPOs supportive of renewable energy are faced with the conundrum of either engaging dominant actors directly through more moderate groups or form social movement organizations designed to bring about policy change through peripheral efforts [14,21]. Neither approach has proven effective in Japan. Instead, decentralized networks are being established through local governments and cooperatives in Japan for renewable energy development. This social movement approach has gained strength due, in part, to a lack of trust in the Japanese government's ability to address the situation. The implications of this approach are that, while Japan tries to recover from Fukushima and determine a direction forward institutionally, efforts to address climate change languish.

This begs the question of whether Japan's energy plan for 2030 (20-22\% nuclear; $22-24 \%$ renewable; and $55 \%$ thermal) remains feasible and, if so, how responsive is it to climate change goals?

\section{Conclusions}

The deference in Japanese culture to institutions differs significantly from Western nations, especially the U.S., where strong individualism yields more of a culture of confrontation in energy policy than is the case of Japan [10]. A significant contribution of this paper is the general proposition that private, environmental NPOs in Japan have committed to pursue an independent, decentralized path after the loss of trust in Japanese institutions post-Fukushima. This commitment represents a different approach than that posed by institutional entrepreneurship literature which emphasizes either a change from within the dominant institution or an outsider approach of activism to change the institutional status quo [14,21]. This paper also provides insights into the institutional power of the Ruling Triad in Japan and the closed system described by Hasegawa [4]. The economic miracle of Japan following World War II might not have been possible without such a system and the collective commitment it entailed. On the other hand, some of the social and environmental problems associated with the economic miracle might not have been overlooked for as long.

The general weakness of grassroots efforts and the paucity of private, environmental NPOs in Japan is indeed striking when compared to the U.S. and European countries. However, the cataclysmic nature of the Fukushima nuclear accident has yet to work its way to a conclusion as indicated by election results in October 2016 and legal actions taken in 2017 against the government and TEPCO. The decentralized efforts underway could lead to new spheres of influence and a collective commitment to change.

Future research should compare the institutional structures of Japan and the U.S. in terms of the ability to shift focus from a dominant energy source toward alternatives to address climate change and the Paris COP21 agreement. The rapid growth in funding from third parties for energy policy in the wake of the Citizens v. United case decision by the U.S. Supreme Court raises questions about the status of institutional power regarding U.S. energy policy given that the Clean Power Plan, hailed as "a historic and important step in reducing carbon pollution from power plants", identifies fossil fuel as continuing to be a critical component of America's energy future [22].

Acknowledgments: No external sources of funding were utilized to support this research.

Author Contributions: We wish to thank Tomoyasu Na kamura, Emeritus, Senshu University, Japan, for his helpful insights. Mark Heuer, the first author, conducted the interviews in Japan and developed the theoretical foundation for the paper. Shan Yan, the second author, conducted the quantitative analysis.

Conflicts of Interest: The authors declare no conflict of interest. 


\section{Appendix}

\section{Appendix A.1 History of Japanese Environmental NPOs}

In the 1960s, while anti-pollution campaigns in Japan were frequent, these grassroots efforts lacked the sustained growth of environmental organizations in the U.S. and other developed economies [23]. Many of the grassroots efforts focused on local issues and lacked a national organization and funding sources.

However, the Kyoto Third Conference of Parties (COP3) to the UN Framework Convention on Climate Change in 1997 allowed new and existing NPOs in Japan to connect with global environmental organizations. This exposure assisted Japanese NPOs in gaining access to the resources and capabilities of global environmental organizations. Additionally, the 1998 Nonprofit Organization Law provided the opportunity for legal status for Japanese NPOs, but did not provide for tax exempt contributions and required extensive registration requirements with the government [24].

Regarding the institutional structure of NPOs, Academic A1 noted that the NPO law created the opportunity for bureaucratic capture of environmental NPOs as some companies utilized the opportunity to fund new NPOs and place retired employees on the board of the NPOs:

"Each company gives lots of funding to NPO groups as retired employees from the companies use company funding to form the NPO. At age 55, employees are asked to retire. So, these people move first to companies in the NPO sector. Companies give money for the NPOs where the retirees go. As a result, this gives the NPO a lot of power to make political policy because all three groups know each other since the bureaucracy is already very involved in the EPCOs like TEPCO."

The creation and funding of NPOs added to an array of environmental NPOs. With the passage of the NPO law, the Japanese environmental NPO institutional structure included: (1) established, private NPOs, (2) new, private NPOs; (3) business-funded NPOs; and (4) global NPOs, which increased in number, scale and scope after the Kyoto COP. The result was confusion and uncertainty about the strategic inclinations of environmental NPOs, as it became possible for a pro-nuclear energy NPO to have a name indicative of a pro-renewable energy NPO. NPO1 [7] observed:

"not all NPOs are what they first seem to be. Also, there are more than 400 other local community groups against nuclear but they can become coopted if they receive government funds. NPOs funded by business or the government may be indistinguishable from authentic environmental NPOs without careful study."

\section{Appendix A.2 The Post-Fukushima Nuclear Accident Context}

The 2011 Great East Japan Earthquake raised fundamental questions about the electricity system's ability to prevent and respond to accidents. The International Atomic Energy Agency (IAEA) classified the nuclear accident at the Fukushima nuclear power plant as level 7, the most serious category, resulting in a major release of radioactive material with widespread health and environmental effects [5].

The inadequate response by the government and TEPCO, the operator of the Fukushima plant, intensified public anxiety about nuclear power. The electricity system had difficulty coping with the shortages caused by the accident. For example, electricity surpluses in some regions could not offset shortages elsewhere due to inadequate interconnection facilities. In addition, weak market mechanisms forced the government to cope with shortages by relying on inefficient policies, such as rolling blackouts and across-the board cuts, as well as increased usage of fossil fuel-based generation systems [4].

The tragedy of the Great East Japan Earthquake prompted the government to launch a debate on the country's energy strategy, including the role for nuclear power. Japan had strong incentives to promote nuclear power [19]. First, it was an effective option to raise Japan's low energy self-sufficiency ratio of $4 \%$ in 2009, one of the lowest in the OECD area, and reduce its vulnerability to energy shocks. 
Second, nuclear energy would help Japan achieve its target for reducing GHG emissions given that nuclear power does not generate $\mathrm{CO}_{2}$. Third, the nuclear power industry was a potential growth engine for Japan, one of the few countries with experience in building and operating nuclear power plants.

In April 2013, with the Democratic Party in power, the Cabinet decided on an electricity reform plan with major reforms planned by 2020, including the full liberalization of the electricity retail market and legal unbundling. (Previously, Japan had instituted a Feed-in-Tariff (FiT), approved when the Democratic Party was in power for three years, which allowed for independent power producers of significant scale to provide renewable energy to the national power grid.)

Three main reform objectives were spelled out:

- Ensure the freedom of choice of electricity for all people.

- Allow everyone to create electricity.

- Deliver electricity widely and neutrally.

However, a Basic Energy Plan (BEP), which served as the first policy action on a future energy plan post-Fukushima, was approved by the Cabinet in April 2014. It affirmed the importance of nuclear power generation as a base load capacity in Japan, while also supporting the growth of renewable energy in the future [24].

In terms of political and institutional responses to Fukushima, possibly indicative of openings in political opportunities for renewable energy, in October 2016, "a nuclear-power skeptic won a gubernatorial race in the Japanese prefecture hosting the world's largest nuclear plant, in a blow to Prime Minister Abe's energy policy" [25] (p. A8). In October 2017, the Fukushima District court ordered the government and TEPCO to pay $\$ 4.4$ million plus additional charges to people who fled radiation released after a tsunami flooded the power plant. TEPCO, as of October 2017, has paid $\$ 67$ billion in compensation to residents affected by the Fukushima meltdown [26].

\section{References}

1. Sine, D.S.; David, R.J. Environmental Jolts, Institutional Change, and the Creation of Entrepreneurial Opportunity in the U.S. Electric Power Industry. Res. Policy 2003, 32, 185-207. [CrossRef]

2. Broadbent, J. Environmental Politics in Japan: Networks of Power and Protest; Oxford University Press: New York, NY, USA, 1999.

3. Fukushima's Appalling Death Toll. Editorial. Japan Times, 1 March 2014.

4. Hasegawa, K. Facing Nuclear Risks: Lessons from the Fukushima Nuclear Disaster. Int. J. Jpn. Sociol. 2012, 21, 84-91. [CrossRef]

5. Funabashi, H. Why the Fukushima Nuclear Disaster is a Man-made Calamity. Int. J. Jpn. Sociol. 2012, 21, 65-75. [CrossRef]

6. Hasegawa, K.A. Comparative Study of Social Movements for a Post-Nuclear Energy Era in Japan and the USA. In East Asian Social Movements; Broadbent, J., Brockman, V., Eds.; Springer Science + Business Media: Berlin, Germany, 2011.

7. Heuer, M. Interviews with three academics and five NPO managers in Japan. Fall, unpublished work. 2015.

8. Dreiling, M.; Wolf, B. Environmental Movement Organizations and Political Strategy. Org. Environ. 2001, 14, 34-54. [CrossRef]

9. Broadbent, J.; Ishio, Y. The 'Embedded Broker' State: Social Networks and Political Organization in Japan. In Networks, Markets and the Pacific Rim: Studies in Strategy; Fruin, W.M., Ed.; Oxford University Press: New York, NY, USA, 1998.

10. Hofstede, G. Culture's Consequences: Company Values, Behaviors, Institutions, and Organizations across Nations, 2nd ed.; Sage: Thousand Oaks, CA, USA, 2001.

11. Jones, G.R.; George, J.R. The Experience and Evolution of Trust: Implications for Cooperation and Teamwork. Acad. Manag. Rev. 1998, 23, 531-546.

12. Korea Stick to Coal Plant Plans. Reuters. Japan Times, 17 December 2015; p. 1.

13. Moorman, C.; Deshpande, R.; Zaltman, G. Factors Affecting Trust in Market Research Relationships. J. Mark. 1993, 57, 81-101. [CrossRef] 
14. Hardy, C.; Maguire, C. Institutional Entrepreneurship. In The Sage Handbook of Organizational Institutionalism; Greenwood, R., Oliver, C., Suddaby, R., Sahlin-Andersson, K., Eds.; Sage: London, UK, 2008.

15. Schneiberg, M. Organizational heterogeneity and the production of new forms: Politics, social movements and mutual companies in American fire insurance, 1900-1930. In Social Structure and Organizations Revisited (Research In the Sociology of Organizations, Volume 19); Lounsbury, M., Ventresca, M.J., Eds.; Emerald Group Publishing Limited: Bingley, UK, 2002; pp. 39-89.

16. Levy, D.; Scully, M. The Institutional Entrepreneur as Modern Prince: The Strategic Face of Power in Contested Fields. Organ. Stud. 2007, 28, 971-991. [CrossRef]

17. Berg, B. Qualitative Research Methods for the Social Sciences, 3rd ed.; Allyn and Bacon: Needham Heights, MA, USA, 1998.

18. ERCA. Environmental Restoration and Conservation Agency. Available online: http://www.erca.go.jp/ jfge/english (accessed 29 April 2014).

19. Miyadai, S. Pitfalls of the "Nuclear Power Reduction" Movement. Int. J. Jpn. Sociol. 2012, 21, 98-107. [CrossRef]

20. Union of Local Governments in Japan to Triple Renewable Energy Output in 2020. 19 April 2014. Available online: www.japanfs.org (accessed on 4 January 2016).

21. Maguire, S. Institutional entrepreneurship. In International Encyclopedia of Organization Studies; Clegg, S., Bailey, J.R., Eds.; Sage: London, UK, 2007; pp. 674-678.

22. U.S. Environmental Protection Agency. Overview of the Clean Power Plan: Cutting Carbon Pollution from Power Plants. 2015. Available online: epa.gov/cleanpowerplan (accessed on 4 January 2016).

23. Dreiling, M.; Lougee, N.; Nakamura, T. After Fukushima: The Silence of Environmental Organizations on Nuclear Catastrophe. 2015. Available online: http:/ / www.metropolitiques.eu (accessed on 22 September 2015).

24. Goto, M.; Sueyoshi, T. Electric Power Market Reform in Japan after Fukushima Daiichi Nuclear Plant Disaster: Issues and Future Direction. Int. J. Energy Sect. Manag. 2015, 9, 336-360. [CrossRef]

25. Nakamichi, T. Nuclear skeptic wins vote in Japan. The Wall Street Journal, 17 October 2016; p. A8.

26. Negishi, M. Redress ordered in Fukushima case. The Wall Street Journal, 11 October 2017; p. A11.

(C) 2018 by the authors. Licensee MDPI, Basel, Switzerland. This article is an open access article distributed under the terms and conditions of the Creative Commons Attribution (CC BY) license (http://creativecommons.org/licenses/by/4.0/). 